\title{
Detection of circulating tumour cells before and following adjuvant chemotherapy and long-term prognosis of early breast cancer
}

\author{
Alexios Matikas ${ }^{1,2}{ }^{\boxplus}$, Athanasios Kotsakis ${ }^{3}$, Stella Apostolaki ${ }^{4}$, Helen Politaki ${ }^{4}$, Maria Perraki ${ }^{4}$, Kostas Kalbakis $^{5}$, Michalis Nikolaou $^{6}$, \\ Panagiota Economopoulou', Dora Hatzidaki ${ }^{4,8}$ and Vassilis Georgoulias ${ }^{4,8}$
}

(c) The Author(s) 2022

\begin{abstract}
BACKGROUND: The detection of circulating tumour cells (CTC) is prognostic for disease recurrence in early breast cancer (BC). This study aims to investigate whether this prognostic effect persists or varies over time.

METHODS: The study population consisted of prospectively included stage I-III BC patients. The presence of CK19 mRNA-positive CTC in the peripheral blood was evaluated before and after adjuvant chemotherapy, using a real-time RT-PCR assay. Longitudinal samples were collected for a subset of patients.

RESULTS: Baseline CTC data were available from 1220 patients, while 1132 had both pre- and post-therapy data. After a median follow-up of 134.1 months, CTC positivity at baseline was associated with shorter overall survival $\left(\mathrm{OS} ; \mathrm{HR}_{\mathrm{adj}}=1.72,95 \% \mathrm{Cl} 1.34-2.21\right.$, $p<0.001)$. For disease-free survival, an interaction with time $(p=0.045)$ was observed. CTC positivity predicted early (within 5 years; $\left.\mathrm{HR}_{\mathrm{adj}}=1.76,95 \% \mathrm{Cl} 1.33-2.32, p<0.001\right)$ but not late recurrence $\left(\mathrm{HR}_{\mathrm{adj}}=1.10,95 \% \mathrm{Cl} 0.79-1.53, p=0.577\right)$. Following adjuvant chemotherapy, more patients converted from CTC-positive to CTC-negative than vice versa $(p<0.001)$. Ten-year OS was $68.6 \%$ for $+/+$ and $86.7 \%$ for $-/-$ group $(p<0.001)$. CTC status at follow-up predicted disease recurrence.

CONCLUSION: CTC detection pre- and post-adjuvant chemotherapy is prognostic for early relapse, supporting investigations for novel adjuvant therapeutic approaches.
\end{abstract}

British Journal of Cancer (2022) 126:1563-1569; https://doi.org/10.1038/s41416-022-01699-5

\section{INTRODUCTION}

Prognostication for early breast cancer $(\mathrm{BC})$ has traditionally relied on clinic-pathologic factors, such as age [1], tumour size [2], hormone receptor (HR) and human epidermal growth factor receptor 2 (HER2) expression [3, 4], as well as nodal status [2, 5]. Since none of these factors are predictive for relative benefit from adjuvant chemotherapy [6], management decisions are based on the absolute risk for recurrence, with patients at the high-risk spectrum deriving higher absolute benefit from chemotherapy. More recently, gene expression profiling has been shown to provide additional prognostic information to traditional factors and large prospective randomised trials have demonstrated that patients at low genomic risk may not benefit from chemotherapy [7-11].

A relative disadvantage of this combined clinic-genomic approach is that all information is obtained at baseline, without considering how the individual patient responds to adjuvant chemotherapy. In contrast, liquid biomarkers can be obtained both pre- and post-therapy, as well as during the follow-up period, facilitating thus a more individualised prognostication. Baseline enumeration of Circulating Tumour Cells (CTC) in particular has been shown to be strongly prognostic for patient survival $[12,13]$. In addition, conversion to CTC-negative from CTC-positive status following chemotherapy distinguishes a population with intermediate prognosis, compared to patients with persistent CTCnegative (best prognosis) or CTC-positive (worst prognosis) status [14]. Whether this prognostic effect persists after a long follow-up period remains unclear. Intriguingly, CTC positivity several years following definite treatment has been associated with late recurrence, albeit with once again short follow-up after CTC detection $[15,16]$.

Our group has previously demonstrated the prognostic value of CTC based on the detection of CK19 mRNA in early BC both at baseline [17] and following adjuvant chemotherapy [18], depending on receptor expression [19], the effect of chemotherapy [20] and endocrine therapy [21] on CTC status, and the feasibility of serial measurements for prognostication [22]. However, published studies at the adjuvant setting have commonly been

\footnotetext{
${ }^{1}$ Department of Oncology-Pathology, Karolinska Institutet, Stockholm, Sweden. ${ }^{2}$ Breast Center, Theme Cancer, Karolinska University Hospital, Stockholm, Sweden. ${ }^{3}$ Department of Medical Oncology, University General Hospital of Larisa, Larisa, Greece. ${ }^{4}$ Laboratory of Tumor Cell Biology, University of Crete, Crete, Greece. ${ }^{5}$ Department of Medical Oncology, University General Hospital of Heraklion, Crete, Greece. ${ }^{6}$ 2nd Department of Medical Oncology, "Agios Savas" Anticancer Hospital, Athens, Greece. ${ }^{7}$ Medical Oncology Unit, Department of Internal Medicine, “ATTIKON”, University Hospital, Athens, Greece. ${ }^{8}$ Hellenic Oncology Research Group, Athens, Greece. ${ }^{\circledR}$ email: alexios.matikas@ki.se
}

Received: 24 July 2021 Revised: 20 December 2021 Accepted: 6 January 2022

Published online: 10 February 2022 
underpowered and with inadequate follow-up in order to assess whether this prognostic effect persists or varies through time [12], which the present study aimed to address.

\section{METHODS \\ Description of the patient cohort}

This is a retrospective analysis of prospectively collected data. A total of 1220 women with operable early or locally advanced, non-metastatic (stage I-III) BC that were treated from 1997 to 2019 in two hospitals in Greece (University Hospital of Heraklion, Crete and Metropolitan General Hospital, Athens) were included in this study. Most of these patients were treated within the context of prospective randomised trials conducted by the Hellenic Oncology Research Group regarding various adjuvant chemotherapy regimens, which have been previously reported [23-26]. Patients not treated within a prospective clinical trial received postoperative therapy in accordance with local practice and national guidelines.

Patient follow-up consisted of medical history and physical examination, with laboratory and imaging studies as indicated, every 3 months for the first 2 years, every 6 months for the next 3 years and yearly thereafter. All treating physicians were blinded to the CK19 mRNA results for their individual patients and all follow-up laboratory and imaging studies to detect disease relapse were performed independently of the CK19 mRNA results. All patients gave their written informed consent for the assessment of CTC status and all prospective clinical trials, as well this specific study on CTC detection, were approved by the Ethics and Scientific Committees of the two institutions.

\section{Methodology of detection of CK19 mRNA-positive CTC}

Peripheral blood ( $20 \mathrm{ml}$ in EDTA) was collected for each sample. To avoid contamination with epithelial skin cells, all blood samples were obtained at the middle of vein puncture after the first $5 \mathrm{~mL}$ of blood was discarded. Sample collection occurred 3-4 weeks after primary surgery and before the initiation of adjuvant chemotherapy, as well as 3-4 weeks after the completion of adjuvant chemotherapy as previously reported [21, 22, 27]. In addition, longitudinal samples were collected for a subset of patients, every 6 months for the first five years following radical surgery and then annually (Supplementary Fig. 1). Persistent CTC positivity was defined as positive status both pre- and post-therapy, at the time the specific sample was obtained.

The procedures of RNA extraction and CDNA synthesis, the real-time RT-PCR assay for the detection of CK19 mRNA-positive CTC as well as its specificity and sensitivity have been previously reported in detail [27]. According to the analytical detection limit of the assay, the presence of $\geq 0.6$ MCF-7 equivalents $/ 5 \mu \mathrm{g}$ of total RNA was considered as a positive result, as previously described in detail $[22,27]$

\section{Statistical analysis}

The aim of this study was to explore whether the prognostic value of CTCS based on the detection of CK19 mRNA persists or varies over time. Due to its descriptive nature, no formal statistical hypothesis was tested. Summary tables (descriptive statistics and/or frequency tables) were provided for all baseline and efficacy variables, as appropriate. Continuous variables were summarised with descriptive statistics ( $\mathrm{n}$, median and range). Qualitative factors were compared by Pearson's chi-squared test or Fisher's exact test whenever appropriate. Differences in positivity rates were assessed using the McNemar test while differences in continuous variables were assessed using the Mann-Whitney U test. Disease-free survival (DFS) was defined as the time from the start date of the treatment to the date of $B C$ recurrence (either locoregional or distant), contralateral BC diagnosis, non-breast second primary cancer or death from any cause, whichever occurred first. Distant relapse-free survival (DRFS) was defined as the time from the start date of the treatment to the date of distant relapse or death from any cause. Overall survival (OS) was defined as the time from the start date of the treatment to the date of death from any cause. Patients alive without any predefined event (relapse or death) were censored at the time of the last known assessment. Time-to-endpoint events (DFS, DRFS, OS) were estimated using the Kaplan-Meier method and the comparisons were computed with the log-rank test. Median follow-up was calculated using the reverse Kaplan-Meier method. The independent effect of presence or absence of CTC at baseline on DFS and OS was examined by fitting a Cox proportional hazards regression model including other potential prognostic factors in the model (age, menopausal status, tumour size, nodal status, tumour grade, hormone receptors, HER2) with the computation of hazard ratios (HRs) and 95\% confidence intervals. The interaction between CTC status and breast cancer subtype with respect to survival outcomes was evaluated in regression models. All statistical tests were two-sided and $p$-values $<0.05$ were considered statistically significant and were not adjusted for multiple comparisons. Data were analysed using the SPSS statistical software, version 22.0 (SPSS Inc., Chicago, IL, USA).

\section{RESULTS}

\section{Patient characteristics}

In total, 1220 patients had available CTC data at baseline (Supplementary Fig. 1). The patients' demographic, clinical and pathologic characteristics, as well as their distribution according to CTC status (positive versus negative), are presented in Table 1. Patients with detectable CK19 mRNA CTC at baseline $(n=483$; $39.6 \%$ ) had larger tumours (Pearson's chi-square $p=0.010$ ), more often positive nodal status (Pearson's chi-square $p=0.028$ ) and higher expression of Ki-67 (Pearson's chi-square $p=0.001$ ). Receptor expression and distribution of immunohistochemistrybased subtypes did not differ between CTC-positive and CTCnegative patients. The majority $(n=1177$ patients, $96.5 \%)$ received adjuvant chemotherapy, most commonly anthracyclineand taxane-based combinations (61.2\%), followed by anthracycline-based regimens (20.3\%) and docetaxel/cyclophosphamide (9.0\%).

\section{Baseline CTC status and prognostication}

After a median follow-up of 134.1 months (range, 3.9-280.6 months), 372 patients (30.5\%) had relapsed, 186 (38.5\%) from the CTC-positive and $186(25.2 \%)$ from the CTCnegative group. The majority (65.0\%) of DFS events were distant metastases (Supplementary Tables 1 and 2). The corresponding 10 -year DFS probability was $63.7 \%$ (95\% Confidence Interval [Cl] 61.0-69.7\%) for CTC-positive versus 75.7\% (95\% Cl 75.0-81.8\%) for CTC-negative patients ( $p<0.001$, Fig. 1).

An interaction between baseline CTC status and time was observed for DFS $(p=0.045)$. When looking into patients with early relapse during the first 5 years following diagnosis, baseline CTC positivity was independently prognostic for shorter DFS at the multivariable analysis when adjusting for age, tumour size, nodal status, grade and hormone receptor status $\left(\mathrm{HR}_{\mathrm{adj}}=1.76,95 \% \mathrm{Cl}\right.$ $1.33-2.32, p<0.001$; Fig. 2). This association was observed across IHC subtypes ( $p_{\text {interaction }} 0.173$ ), although wide confidence intervals were noted for the HER2 + subgroup due to the low number of events (Supplementary Table 3). In contrast, baseline CTC status was not prognostic for delayed ( $>5$ years) relapse $(\mathrm{HR}=1.10,95 \% \mathrm{Cl} 0.79-1.53, p=0.577)$. Similar results were noted for the DRFS endpoint, with baseline CTC positivity being associated with worse DRFS during years $0-5\left(\mathrm{HR}_{\mathrm{adj}}=1.90,95 \%\right.$ $\mathrm{Cl} 1.42-2.56, p<0.001)$ but not beyond 5 years $\left(\mathrm{HR}_{\mathrm{adj}}=1.23,95 \%\right.$ $\mathrm{Cl} 0.87-1.76, p=0.243)$. The lack of prognostic value for delayed relapse was apparent even when focusing on HR-positive disease (univariate Cox regression $\mathrm{HR}=1.31,95 \% \mathrm{Cl} 0.89-1.92, p=0.169$ ).

Similarly, 284 (23.3\%) patients died during the follow-up period, $153(31.7 \%)$ from the CTC-positive and $131(17.8 \%)$ from the CTCnegative group for a 10-year overall survival rate of $72.4 \%(95 \% \mathrm{Cl}$ $70.6-78.6 \%)$ versus $85.2 \%$ (95\% Cl $85.0-90.0 \%)$, respectively $(p<$ 0.001 ). Baseline CTC positivity remained an independent negative prognostic factor at multivariable analysis $\left(\mathrm{HR}_{\mathrm{adj}}=1.72,95 \% \mathrm{Cl}\right.$ 1.34-2.21, $p<0.001$ ) as shown in Table 2 and Supplementary Table 4

\section{Post-therapy CTC dynamics and prognostication}

Both baseline and immediately post-therapy CTC status were available from 1132 patients (92.7\% of the entire cohort). CK19 mRNA was detected in both samples $(+/+)$ in 225 patients 
Table 1. Patients' clinicopathologic characteristics in entire cohort and per baseline CTC status.

\begin{tabular}{|c|c|c|c|c|}
\hline & $\begin{array}{l}\text { All Pts } \\
(n=1220) \\
N(\%)\end{array}$ & $\begin{array}{l}\text { CTCs (+) } \\
(n=483) \\
N(\%)\end{array}$ & $\begin{array}{l}\text { CTCs (-) } \\
(n=737) \\
N(\%)\end{array}$ & $P$-value \\
\hline \multicolumn{5}{|l|}{ Age } \\
\hline $\begin{array}{l}\text { Median } \\
\text { (min-max) }\end{array}$ & $53(25-83)$ & $54(26-83)$ & $53(25-81)$ & 0.870 \\
\hline \multicolumn{5}{|l|}{ Menopausal status } \\
\hline Pre-menopausal & $552(45.2)$ & $225(46.6)$ & $327(44.4)$ & 0.447 \\
\hline Post-menopausal & $668(54.8)$ & $258(53.4)$ & $410(55.6)$ & \\
\hline \multicolumn{5}{|l|}{ Tumour size } \\
\hline$\leq 2 \mathrm{~cm}$ & $505(45.1)$ & $179(37.1)$ & $326(44.5)$ & 0.010 \\
\hline$>2 \mathrm{~cm}$ & $710(63.4)$ & $304(62.9)$ & $406(55.5)$ & \\
\hline NA & $5(0.4)$ & & & \\
\hline \multicolumn{5}{|l|}{ Nodal status } \\
\hline Negative & $460(37.7)$ & $164(34.2)$ & $296(40.4)$ & 0.028 \\
\hline Positive & $752(61.6)$ & $316(65.8)$ & $436(59.6)$ & \\
\hline NA & $8(0.7)$ & & & \\
\hline \multicolumn{5}{|l|}{ Oestrogen receptor } \\
\hline Positive & $809(66.3)$ & $319(66.5)$ & $490(67.3)$ & 0.759 \\
\hline Negative & $399(32.7)$ & $161(33.5)$ & $238(32.7)$ & \\
\hline NA & $12(1.0)$ & & & \\
\hline \multicolumn{5}{|l|}{ Progesterone receptor } \\
\hline Positive & $757(62.0)$ & $291(60.6)$ & $466(64.2)$ & 0.210 \\
\hline Negative & $449(36.8)$ & $189(39.4)$ & $260(35.9)$ & \\
\hline NA & $14(1.2)$ & & & \\
\hline \multicolumn{5}{|l|}{ HER2 } \\
\hline Positive & $247(20.2)$ & $93(19.5)$ & $154(21.3)$ & 0.468 \\
\hline Negative & $953(78.1)$ & $383(80.5)$ & $570(78.7)$ & \\
\hline NA & $20(1.6)$ & & & \\
\hline \multicolumn{5}{|l|}{ Subtype } \\
\hline ER+/HER2- & 755 (61.9) & $291(66.3)$ & $464(64.3)$ & 0.100 \\
\hline HER2+ & $244(20.0)$ & $92(19.4)$ & $152(21.1)$ & \\
\hline TNBC & $198(16.2)$ & $92(19.4)$ & $106(14.7)$ & \\
\hline NA & $23(1.9)$ & & & \\
\hline \multicolumn{5}{|l|}{ Grade } \\
\hline 1 & $24(2.2)$ & $6(1.4)$ & $18(2.7)$ & 0.247 \\
\hline II & $541(48.9)$ & $223(50.7)$ & $318(47.7)$ & \\
\hline III & $541(48.9)$ & $211(48.0)$ & $330(49.5)$ & \\
\hline \multicolumn{5}{|l|}{ Ki-67 } \\
\hline$\leq 20 \%$ & $336(27.5)$ & $107(48.9)$ & $229(63.1)$ & 0.001 \\
\hline$>21 \%$ & $246(20.2)$ & $112(51.1)$ & $134(36.9)$ & \\
\hline NA & $638(52.3)$ & & & \\
\hline \multicolumn{5}{|l|}{ Type of surgery } \\
\hline BCS & $810(66.4)$ & $314(65.0)$ & $496(67.3)$ & 0.179 \\
\hline Mastectomy & $406(33.3)$ & $169(35.0)$ & $237(32.2)$ & \\
\hline NA & $4(0.3)$ & - & $4(0.5)$ & \\
\hline \multicolumn{5}{|c|}{ Adjuvant chemotherapy } \\
\hline TC & $110(9.0)$ & $31(6.4)$ & $79(10.7)$ & 0.066 \\
\hline Anthracycline & $248(20.3)$ & $105(21.7)$ & $143(19.4)$ & \\
\hline $\begin{array}{l}\text { Anthracycline } \\
\text { and Taxane }\end{array}$ & $747(61.2)$ & $308(63.8)$ & $439(59.6)$ & \\
\hline Other Chemo & $72(5.9)$ & $27(5.6)$ & $45(6.1)$ & \\
\hline Endocrine only & $38(3.1)$ & $11(2.3)$ & $27(3.7)$ & \\
\hline No adjuvant & $5(0.4)$ & $1(0.2)$ & $4(0.5)$ & \\
\hline \multicolumn{5}{|l|}{ Adjuvant endocrine } \\
\hline Yes & $976(80.0)$ & 375 (77.6) & $601(81.5)$ & 0.095 \\
\hline No & $244(20.0)$ & $108(22.4)$ & $136(18.5)$ & \\
\hline
\end{tabular}

CTC circulating tumour cell, ER oestrogen receptor, HER2 human epidermal growth factor receptor 2, TC docetaxel/cyclophosphamide, TNBC triplenegative breast cancer.
(19.9\%); 229 patients (20.2\%) had positive pre-therapy but negative post-therapy CTC status $(+/-) ; 114$ patients $(10.1 \%)$ had the opposite $(-/+)$, while 564 patients $(49.8 \%)$ were persistently CTC-negative. More patients converted from CTCpositive to CTC-negative following adjuvant chemotherapy, than vice versa (McNemar's test $p<0.001)$. This pattern was noted across IHC subtypes (Supplementary Table 5).

Long-term survival outcomes differed between these groups: 10year DFS rates were $61.1 \%$ (95\% Cl 55.7-68.3\%) for +/+ group, $67.1 \%$ (95\% Cl 62.7-74.6\%) for +/- group, 65.2\% (95\% Cl 59.4-76.2\%) for $-/+$ group and $78.1 \%$ (95\% Cl 75.4-82.1\%) for -/- group (logrank test: $p<0.001)$. The corresponding 10-year OS rates are shown in Fig. 3.

Compared with patients in the $-/$ - group, those in the $+/+$ had worse DFS and OS in multivariable analysis when adjusted for age, size, nodal status, grade and receptor status (DFS: $\mathrm{HR}_{\mathrm{adj}}=$ $1.88,95 \% \mathrm{Cl} 1.42-2.49, p<0.001 ;$ OS: $\mathrm{HR}_{\mathrm{adj}}=2.12,95 \% \mathrm{Cl}$ 1.54-2.91, $p<0.001)$. Similar results were noted for patients in the $+/-$ and $-/+$ compared with the $-/-$ group [(DFS: $\mathrm{HR}_{\mathrm{adj}}=$ $1.61,95 \% \mathrm{Cl} 1.20-2.18, p=0.002 ;$ OS: $\mathrm{HR}_{\mathrm{adj}}=1.81,95 \% \mathrm{Cl}$ $1.28-2.57, p=0.001)$ and (DFS: $\mathrm{HR}_{\mathrm{adj}}=2.09,95 \% \mathrm{Cl} 1.48-2.97$, $p<0.001$; OS: $\left.\left.\mathrm{HR}_{\mathrm{adj}}=1.90,95 \% \mathrm{Cl} 1.23-2.91, p=0.003\right)\right]$, respectively. However, conversion of CTC status from baseline positive to post-therapy negative did not improve prognosis both in terms of DFS (HR $=0.79,95 \% \mathrm{Cl} 0.59-1.07, p=0.126)$ and OS (HR=0.74, $95 \% \mathrm{Cl} 0.53-1.03, p=0.072$ ), compared to patients that were persistently positive.

Compared with patients in the $-/-$ group, patients with detection of CTC pre- and post-therapy had worse short-term (years 0-5) DFS (HR $=2.09,95 \% \mathrm{Cl} 1.45-3.0, p<0.001)$. However, persistent CTC positivity was not prognostic for late relapse after the 5-year timepoint ( $\mathrm{HR}=1.28,95 \% \mathrm{Cl} 0.83-1.97, p=0.266)$. Similar results were noted for the DRFS endpoint, for both shortterm $\left(\mathrm{HR}_{\mathrm{adj}}=2.33,95 \% \mathrm{Cl} 1.59-3.42, p<0.001\right)$ and long-term prognosis $\left(\mathrm{HR}_{\mathrm{adj}}=1.34,95 \% \mathrm{Cl} 0.85-2.11, p=0.214\right)$.

\section{CTC status during follow-up and risk for delayed relapse}

Serial CTC samples during follow-up were obtained from a subgroup of 185 patients. Their baseline characteristics are presented in Supplementary Table 6, while data availability is shown in Supplementary Fig. 1 and Supplementary Table 7. Data from four timepoints at 1, 2, 3 and 5 years pos-toperatively are presented hereunder, with $62(33.5 \%)$ patients having serial samples from all four timepoints, and 157 (84.9\%) having from at least two. Depending on the timepoint, up to $19.8 \%$ of patients had detectable CTC (Supplementary Table 8). Of the 97 patients with -/- status pre- and post-therapy that had available longitudinal data at least once during follow-up, $8.9 \%$ were positive at 12 months (8/90; Fisher's exact test $p<0.001), 5.2 \%$ at 24 months (4/77; Fisher's exact test $p<0.001), 10 \%$ at 36 months $(6 / 60$; Fisher's exact test $p=0.030)$ and $9.8 \%$ at 60 months (4/41; Fisher's exact test $p<0.001$ ).

CTC positivity at these four timepoints was generally associated with worse outcomes, although wide confidence intervals were noted due to the low number of events (at 12 months: $\mathrm{HR}=2.36$, $95 \% \mathrm{Cl} 1.15-4.85, p=0.02$; at 24 months: $\mathrm{HR}=5.72,95 \% \mathrm{Cl}$ 2.38-13.78, $p<0.001$; at 36 months: $\mathrm{HR}=1.92,95 \% \mathrm{Cl} 0.66-5.6$, $p=0.229$; at 60 months: $\mathrm{HR}=3.01,95 \% \mathrm{Cl} 0.62-14.52, p=0.169$ ).

\section{DISCUSSION}

In this large retrospective analysis of samples collected from prospectively enrolled patients with a median follow-up of more than 11 years, we demonstrate that the prognostic effect of both pre- and post-therapy CTC status varies through time, with CTC detection being prognostic for early disease recurrence. In addition, obtaining new CTC samples during follow-up could provide additional prognostic information for patients already 


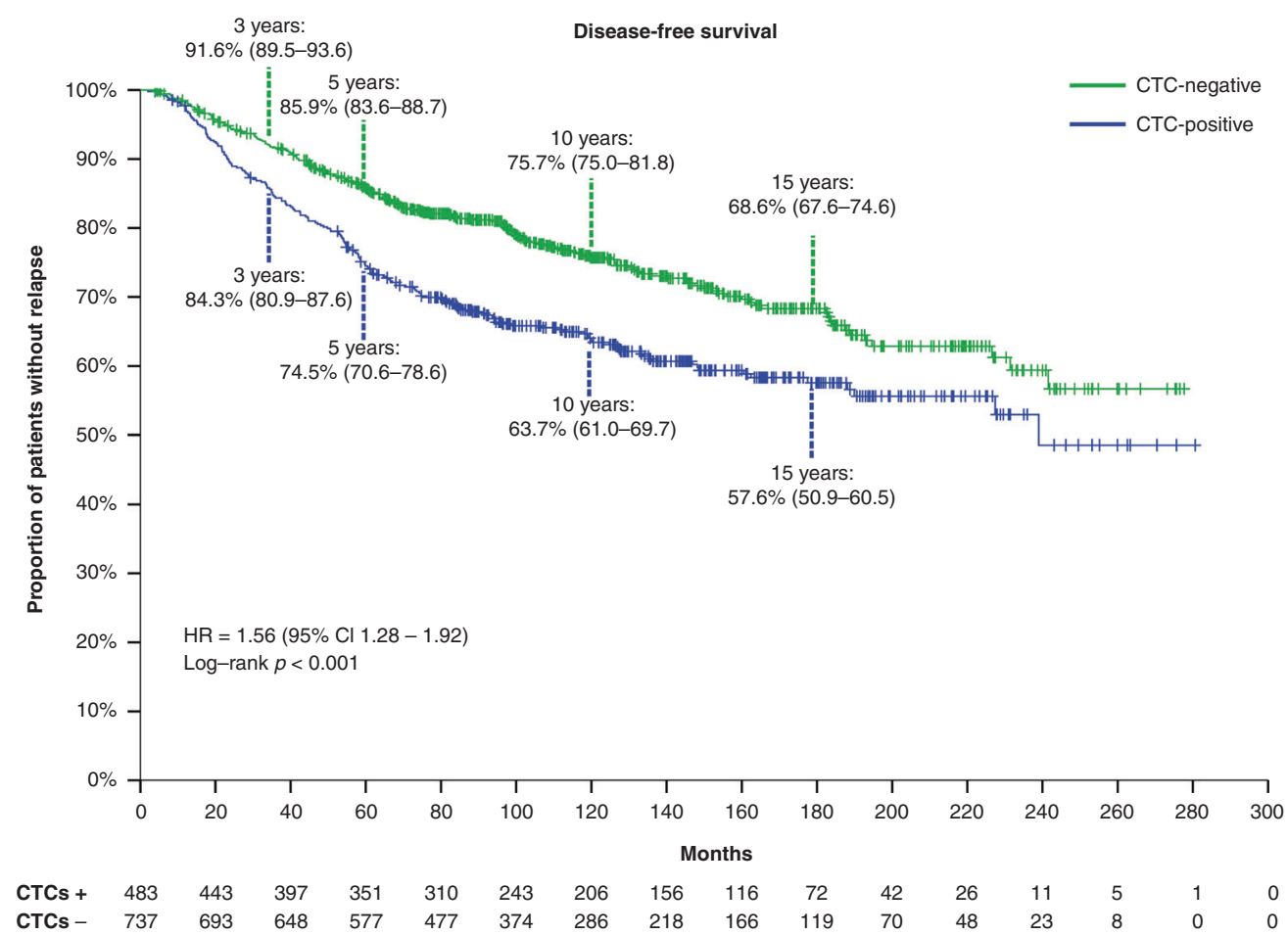

Fig. 1 Kaplan-Meier curve for disease-free survival according to baseline (pre-therapy) CTC status. Cl confidence interval, CTC circulating tumour cells, HR hazard ratio.

Multivariable analysis for disease-free survival during years $0-5$

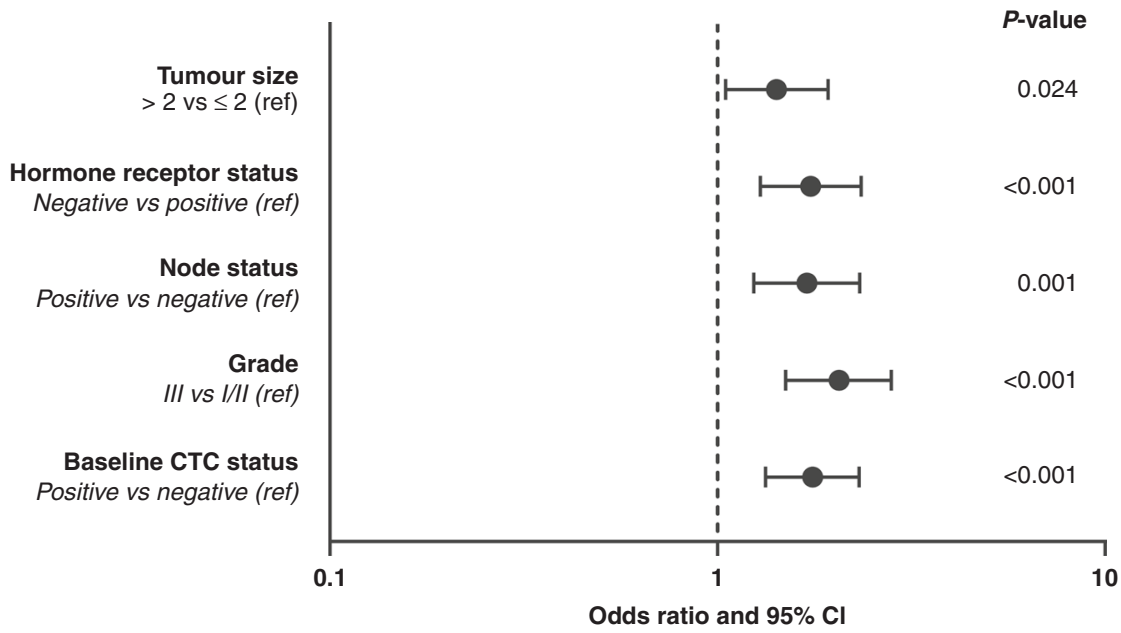

Fig. 2 Multivariable Cox regression model for the endpoint of disease-free survival during years $\mathbf{0}-5$. $\mathrm{Cl}$ confidence interval, $\mathrm{CTC}$ circulating tumour cell, ref reference.

surviving without relapse several years following primary surgery. Despite the exploratory nature of our study, these two findings have potential clinical implications, since they support the role of CTC for risk stratification that might affect management decisions at the adjuvant setting. On one hand, by supporting novel individualised adjuvant strategies aiming to eradicate the minimal residual disease (MRD) and on the other hand, by distinguishing a population with MRD years following primary treatment and thus potentially in need of extended endocrine therapy.

An inherent disadvantage of adjuvant chemotherapy is that there is no indication whether the individual patient has already been cured, leading potentially to both over- and undertreatment. Prolonging the duration of adjuvant chemotherapy indiscriminately does not improve outcomes [28]. Monitoring MRD following surgery and chemotherapy, either with CTC, circulating tumour DNA or extracellular vesicles, is an avenue worth pursuing in an effort to individualise further treatment [29]. Novel adjuvant approaches aiming to eradicate MRD are emerging following the highly successful paradigm of prolonged HER2-blockade, such as long-term metronomic adjuvant chemotherapy for triple-negative BC [30] or adjuvant cyclin-dependent kinase (CDK) 4/6 inhibitors for HR-positive, HER2-negative BC [31]. The conflicting results regarding the latter underscore the need for better risk stratification and patient selection [32, 33]. Baseline and post-therapy CTC positivity was associated with worse outcomes in our study, with detectable MRD being an independent predictor for early relapse. 
Although speculative, this patient population may be an excellent target group for early consolidation therapy. Whether this approach is successful in eradicating MRD and improving survival should be the aim of prospective randomised studies with the endpoint of CTC clearance. Small randomised studies of HER2

Table 2. Univariate and multivariable analysis of baseline clinicopathologic factors for overall survival.

\begin{tabular}{|c|c|c|c|c|}
\hline \multirow[b]{2}{*}{ Factors } & \multicolumn{2}{|c|}{ Univariate analysis } & \multicolumn{2}{|c|}{ Multivariable analysis } \\
\hline & $\begin{array}{l}\text { Hazard ratio } \\
(95 \% \text { C.I) }\end{array}$ & $P$-value & $\begin{array}{l}\text { Hazard ratio } \\
\text { (95\% C.I) }\end{array}$ & $P$-value \\
\hline Age & & $<0.001$ & & 0.015 \\
\hline$\leq 60$ & 1 (reference) & & 1 (reference) & \\
\hline$>60$ & $1.64(1.29-2.08)$ & & $1.38(1.07-1.78)$ & \\
\hline T size & & $<0.001$ & & $<0.001$ \\
\hline$\leq 2 \mathrm{~cm}$ & 1 (reference) & & 1 (reference) & \\
\hline$>2 \mathrm{~cm}$ & $2.38(1.81-3.13)$ & & $1.89(1.41-2.53)$ & \\
\hline Nodes & & $<0.001$ & & $<0.001$ \\
\hline Negative & 1 (reference) & & 1 (reference) & \\
\hline Positive & $1.95(1.39-2.29)$ & & $1.85(1.37-2.50)$ & \\
\hline Grade & & $<0.001$ & & 0.002 \\
\hline I/II & 1 (reference) & & 1 (reference) & \\
\hline III & $1.78(1.39-2.29)$ & & $1.54(1.18-2.02)$ & \\
\hline $\begin{array}{l}\text { Hormone } \\
\text { receptor }\end{array}$ & & 0.022 & & 0.022 \\
\hline Positive & 1 (reference) & & 1 (reference) & \\
\hline Negative & $1.35(1.04-1.74)$ & & $1.39(1.05-1.84)$ & \\
\hline CTC & & $<0.001$ & & $<0.001$ \\
\hline Positive & $1.74(1.38-2.20)$ & & $1.72(1.34-2.21)$ & \\
\hline Negative & 1 (reference) & & 1 (reference) & \\
\hline
\end{tabular}

$\mathrm{Cl}$ confidence interval, CTC circulating tumour cell. targeted agents for HER2-negative BC have demonstrated the feasibility of this approach and reported promising results [34-36].

The natural history of early BC, especially HR-positive disease, is prolonged with a steady annual rate of recurrence and a continuously increasing cumulative risk of recurrence [37]. While extended endocrine therapy has been shown to marginally decrease the risk for recurrence [38], patient selection is challenging. Clinical and pathologic factors [39] and gene expression profiling [40-43] are used to select patients at high risk for late recurrence. However, such an approach is based on baseline risk stratification and ignores the fact that many patients with HR-positive disease surviving at least 5 years are presumably cured and thus overtreated if exposed to extended therapy [44]. As a result, the selection of patients for extended endocrine therapy according to persistent MRD is an intriguing approach. In our study, persistent CTC positivity at 1, 2, 3 and 5 years following adjuvant chemotherapy was associated with worse patient outcomes, confirming previous reports on CTC enumeration based on another assay $[15,16]$. Further studies are needed to show if this adverse outcome may be overcome by continuing or changing endocrine therapy.

Despite the large size and prolonged follow-up of our study, several limitations of our exploratory analysis should be acknowledged. Firstly, various chemotherapy regimens were used, and patient allocation to treatment was not randomised. As a result, the relative contribution of chemotherapy to CTC status conversion and prognosis cannot be assessed. Furthermore, robust conclusions regarding the potential impact of CTC clearance cannot be drawn. While CTC persistence post-therapy is a potential marker of chemoresistance, their disappearance is a function of the sensitivity of the method, thus multiple longitudinal samples are needed for confirmation. However, in our study there were few patients with CTC samples at long-term follow-up and few events in this group, rendering these analyses purely exploratory and prone to associations by chance, considering that the increase in the familywise error rate was

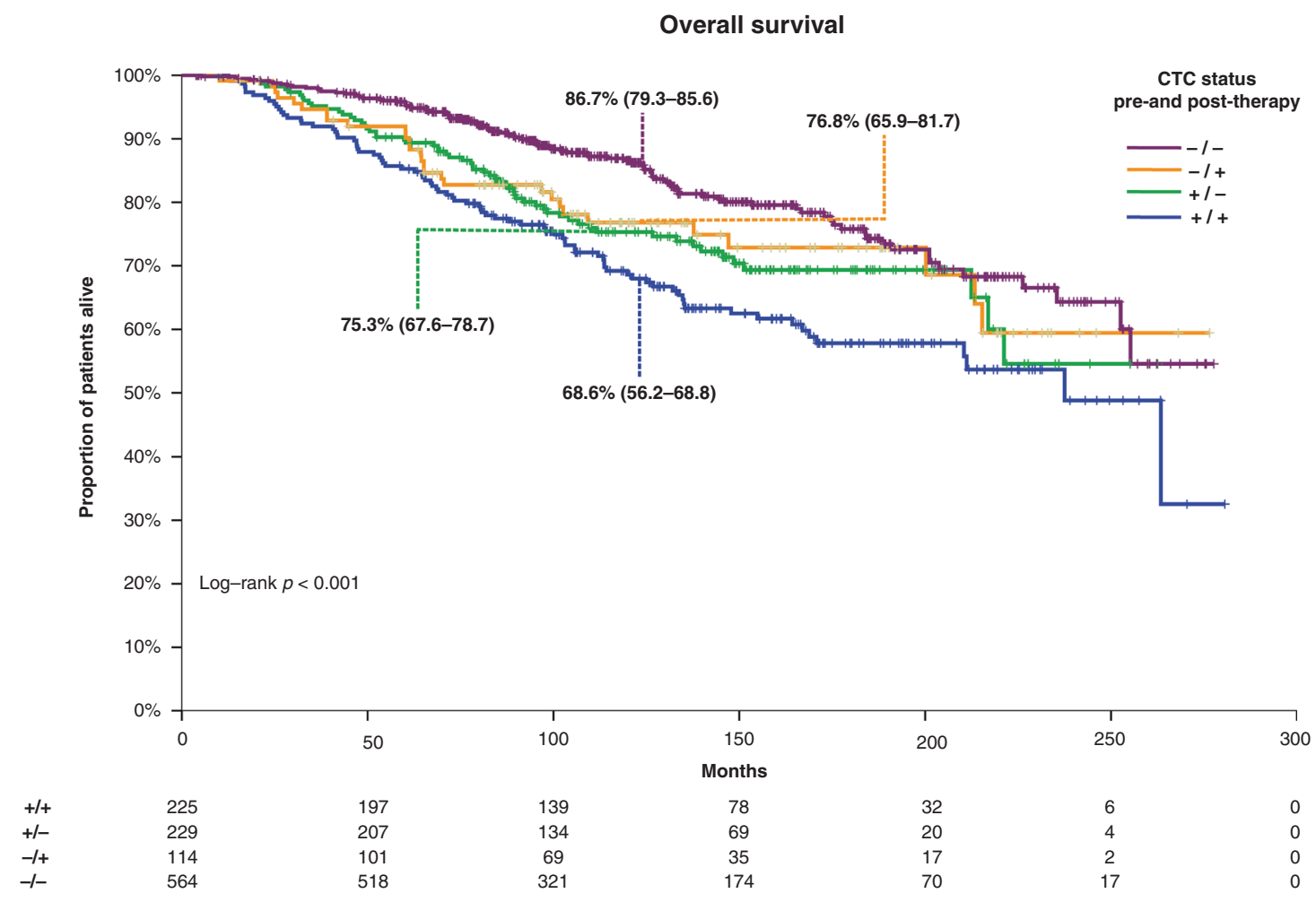

Fig. 3 Kaplan-Meier curve for overall survival according to pre- and post-therapy CTC status. CTC circulating tumour cells. 
not controlled in the reported analyses. Finally, the methodology used for CTC detection in this study is developed in-house and is not approved for routine clinical use. Nevertheless, the overall agreement of this assay with the more commonly used CellSearch system (Menarini Silicon Biosystems Inc, Italy) is up to $73.5 \%$, depending on the CTC cut-off [45].

In conclusion, the prognostic effect of pre- and post- adjuvant chemotherapy CTC status persists after long follow-up. Detection of baseline and post-therapy MRD was shown to be associated with early and not delayed relapse, which supports further investigations for alternative adjuvant therapy approaches. The potential clinical implications support the conduct of randomised studies of early BC with CTC clearance as the primary endpoint.

\section{DATA AVAILABILITY}

The datasets that support the findings of this study are available from the corresponding (AM) or the senior author (VG) upon reasonable request.

\section{REFERENCES}

1. Partridge $A H$, Hughes $M E$, Warner ET, Ottesen RA, Wong $\mathrm{YN}$, Edge $\mathrm{SB}$, et al. Subtype-dependent relationship between young age at diagnosis and breast cancer survival. J Clin Oncol. 2016;34:3308-14.

2. Carter $\mathrm{CL}$, Allen $\mathrm{C}$, Henson DE. Relation of tumor size, lymph node status, and survival in 24,740 breast cancer cases. Cancer. 1989;63:181-7.

3. Colleoni M, Sun Z, Price KN, Karlsson P, Forbes JF, Thurlimann B, et al. Annual hazard rates of recurrence for breast cancer during 24 years of follow-up: results from the International Breast Cancer Study Group Trials I to V. J Clin Oncol. 2016;34:927-35.

4. Tandon AK, Clark GM, Chamness GC, Ullrich A, McGuire WL. HER-2/neu oncogene protein and prognosis in breast cancer. J Clin Oncol. 1989;7:1120-8.

5. Andersson Y, Frisell J, Sylvan M, de Boniface J, Bergkvist L. Breast cancer survival in relation to the metastatic tumor burden in axillary lymph nodes. J Clin Oncol. 2010;28:2868-73.

6. Early Breast Cancer Trialists' Collaborative G, Peto R, Davies C, Godwin J, Gray R, Pan $\mathrm{HC}$, et al. Comparisons between different polychemotherapy regimens for early breast cancer: meta-analyses of long-term outcome among 100,000 women in 123 randomised trials. Lancet. 2012;379:432-44.

7. Kalinsky K, Barlow WE, Gralow JR, Meric-Bernstam F, Albain KS, Hayes D, et al. 21Gene Assay to Inform Chemotherapy Benefit in Node-Positive Breast Cancer. N Engl J Med. 2021;385:2336-47.

8. Cardoso F, van't Veer LJ, Bogaerts J, Slaets L, Viale G, Delaloge S, et al. 70-gene signature as an aid to treatment decisions in early-stage breast cancer. N Engl J Med. 2016;375:717-29.

9. Piccart $M$, van 't Veer L, Poncet C, Lopes Cardozo JMN, Delaloge S, Pierga JY, et al. 70-gene signature as an aid for treatment decisions in early breast cancer: updated results of the phase 3 randomised MINDACT trial with an exploratory analysis by age. Lancet Oncol. 2021;22:476-88.

10. Sparano JA, Gray RJ, Ravdin PM, Makower DF, Pritchard KI, Albain KS, et al. Clinical and genomic risk to guide the use of adjuvant therapy for breast cancer. $\mathrm{N}$ Engl J Med. 2019;380:2395-405.

11. Sparano JA, Gray RJ, Makower DF, Albain KS, Saphner TJ, Badve SS, et al. Clinical outcomes in early breast cancer with a high 21-gene recurrence score of 26 to 100 assigned to adjuvant chemotherapy plus endocrine therapy: a secondary analysis of the TAILORx randomized clinical trial. JAMA Oncol. 2020;6:367-74.

12. Thery L, Meddis A, Cabel L, Proudhon C, Latouche A, Pierga JY, et al. Circulating tumor cells in early breast cancer. JNCI Cancer Spectr. 2019;3:pkz026.

13. Janni WJ, Rack B, Terstappen LW, Pierga JY, Taran FA, Fehm T, et al. Pooled analysis of the prognostic relevance of circulating tumor cells in primary breast cancer. Clin Cancer Res. 2016;22:2583-93.

14. Rack B, Schindlbeck C, Juckstock J, Andergassen U, Hepp P, Zwingers T, et al. Circulating tumor cells predict survival in early average-to-high risk breast cancer patients. J Natl Cancer Inst. 2014;106. https://academic.oup.com/jnci/issue/106/5.

15. Trapp E, Janni W, Schindlbeck C, Juckstock J, Andergassen U, de Gregorio A, et al. Presence of circulating tumor cells in high-risk early breast cancer during followup and prognosis. J Natl Cancer Inst. 2019;111:380-7.

16. Sparano J, O'Neill A, Alpaugh K, Wolff AC, Northfelt DW, Dang CT, et al. Association of circulating tumor cells with late recurrence of estrogen receptorpositive breast cancer: a secondary analysis of a randomized clinical trial. JAMA Oncol. 2018;4:1700-6.

17. Xenidis N, Perraki M, Kafousi M, Apostolaki S, Bolonaki I, Stathopoulou A, et al. Predictive and prognostic value of peripheral blood cytokeratin-19 mRNA- positive cells detected by real-time polymerase chain reaction in node-negative breast cancer patients. J Clin Oncol. 2006;24:3756-62.

18. Xenidis N, Ignatiadis M, Apostolaki S, Perraki M, Kalbakis K, Agelaki S, et al. Cytokeratin-19 mRNA-positive circulating tumor cells after adjuvant chemotherapy in patients with early breast cancer. J Clin Oncol. 2009;27:2177-84.

19. Ignatiadis $M$, Xenidis N, Perraki M, Apostolaki S, Politaki E, Kafousi M, et al. Different prognostic value of cytokeratin-19 mRNA positive circulating tumor cells according to estrogen receptor and HER2 status in early-stage breast cancer. J Clin Oncol. 2007;25:5194-202.

20. Xenidis N, Perraki M, Apostolaki S, Agelaki S, Kalbakis K, Vardakis N, et al. Differential effect of adjuvant taxane-based and taxane-free chemotherapy regimens on the CK-19 mRNA-positive circulating tumour cells in patients with early breast cancer. Br J Cancer. 2013;108:549-56.

21. Xenidis N, Markos V, Apostolaki S, Perraki M, Pallis A, Sfakiotaki G, et al. Clinical relevance of circulating CK-19 mRNA-positive cells detected during the adjuvant tamoxifen treatment in patients with early breast cancer. Ann Oncol. 2007;18:1623-31.

22. Saloustros E, Perraki M, Apostolaki S, Kallergi G, Xyrafas A, Kalbakis K, et al. Cytokeratin-19 mRNA-positive circulating tumor cells during follow-up of patients with operable breast cancer: prognostic relevance for late relapse. Breast Cancer Res. 2011;13:R60.

23. Mavroudis D, Saloustros E, Boukovinas I, Papakotoulas P, Kakolyris S, Ziras N, et al. Sequential vs concurrent epirubicin and docetaxel as adjuvant chemotherapy for high-risk, node-negative, early breast cancer: an interim analysis of a randomised phase III study from the Hellenic Oncology Research Group. Br J Cancer. 2017;117:164-70.

24. Mavroudis D, Matikas A, Malamos N, Papakotoulas P, Kakolyris S, Boukovinas I, et al. Dose-dense FEC followed by docetaxel versus docetaxel plus cyclophosphamide as adjuvant chemotherapy in women with HER2-negative, axillary lymph node-positive early breast cancer: a multicenter randomized study by the Hellenic Oncology Research Group (HORG). Ann Oncol. 2016;27:1873-8.

25. Saloustros E, Malamos N, Boukovinas I, Kakolyris S, Kouroussis C, Athanasiadis A, et al. Dose-dense paclitaxel versus docetaxel following FEC as adjuvant chemotherapy in axillary node-positive early breast cancer: a multicenter randomized study of the Hellenic Oncology Research Group (HORG). Breast Cancer Res Treat. 2014;148:591-7.

26. Polyzos A, Malamos N, Boukovinas I, Adamou A, Ziras N, Kalbakis K, et al. FEC versus sequential docetaxel followed by epirubicin/cyclophosphamide as adjuvant chemotherapy in women with axillary node-positive early breast cancer: a randomized study of the Hellenic Oncology Research Group (HORG). Breast Cancer Res Treat. 2010;119:95-104.

27. Stathopoulou A, Gizi A, Perraki M, Apostolaki S, Malamos N, Mavroudis D, et al. Real-time quantification of CK-19 mRNA-positive cells in peripheral blood of breast cancer patients using the lightcycler system. Clin Cancer Res. 2003;9:5145-51.

28. Shulman LN, Cirrincione CT, Berry DA, Becker HP, Perez EA, O'Regan R, et al. Six cycles of doxorubicin and cyclophosphamide or Paclitaxel are not superior to four cycles as adjuvant chemotherapy for breast cancer in women with zero to three positive axillary nodes: Cancer and Leukemia Group B 40101. J Clin Oncol. 2012;30:4071-6.

29. Ignatiadis M, Sledge GW, Jeffrey SS. Liquid biopsy enters the clinic-implementation issues and future challenges. Nat Rev Clin Oncol. 2021;18:297-312.

30. Bi XW, Hua X, Yuan ZY. Effect of adjuvant metronomic capecitabine on diseasefree survival among patients with early-stage triple-negative breast cancer-reply. JAMA. 2021;325:1793.

31. Johnston SRD, Harbeck N, Hegg R, Toi M, Martin M, Shao ZM, et al. Abemaciclib combined with endocrine therapy for the adjuvant treatment of HR+, HER2-, nodepositive, high-risk, early breast cancer (monarchE). J Clin Oncol. 2020;38:3987-98.

32. Mayer EL, Dueck AC, Martin M, Rubovszky G, Burstein HJ, Bellet-Ezquerra M, et al. Palbociclib with adjuvant endocrine therapy in early breast cancer (PALLAS): interim analysis of a multicentre, open-label, randomised, phase 3 study. Lancet Oncol. 2021;22:212-22.

33. Loibl S, Marme F, Martin M, Untch M, Bonnefoi H, Kim SB, et al. Palbociclib for residual high-risk invasive HR-positive and HER2-negative early breast cancerthe penelope-B trial. J Clin Oncol. 2021;39:1518-30.

34. Ignatiadis $M$, Litiere $S$, Rothe $F$, Riethdorf $S$, Proudhon $C$, Fehm $T$, et al. Trastuzumab versus observation for HER2 nonamplified early breast cancer with circulating tumor cells (EORTC 90091-10093, BIG 1-12, Treat CTC): a randomized phase II trial. Ann Oncol. 2018;29:1777-83.

35. Fehm T, Mueller V, Banys-Paluchowski M, Fasching PA, Friedl TW, Hartkopf A, et al. Abstract PD3-12: Efficacy of the tyrosine kinase inhibitor lapatinib in the treatment of patients with HER2-negative metastatic breast cancer and HER2positive circulating tumor cells-results from the randomized phase III DETECT III trial. Cancer Res. 2021;81:PD3-12. https://cancerres.aacrjournals.org/content/81/ 4_Supplement/PD3-12.article-info. 
36. Georgoulias V, Bozionelou V, Agelaki S, Perraki M, Apostolaki S, Kallergi G, et al. Trastuzumab decreases the incidence of clinical relapses in patients with early breast cancer presenting chemotherapy-resistant CK-19mRNA-positive circulating tumor cells: results of a randomized phase II study. Ann Oncol. 2012;23:1744-50.

37. Pan H, Gray R, Braybrooke J, Davies C, Taylor C, McGale P, et al. 20-year risks of breast-cancer recurrence after stopping endocrine therapy at 5 years. $\mathrm{N}$ Engl J Med. 2017;377:1836-46.

38. Early Breast Cancer Trialists Collaborative Group. Effects of prolonging adjuvant aromatase inhibitor therapy beyond five years on recurrence and cause-specific mortality: An EBCTCG meta-analysis of individual patient data from 12 randomised trials including 24,912 women. Cancer Res. 2019;79:GS3-03. https:// cancerres.aacrjournals.org/content/79/4 Supplement/GS3-03.

39. Dowsett M, Sestak I, Regan MM, Dodson A, Viale G, Thurlimann B, et al. Integration of clinical variables for the prediction of late distant recurrence in patients with estrogen receptor-positive breast cancer treated with 5 years of endocrine therapy: CTS5. J Clin Oncol. 2018;36:1941-8.

40. Sestak I, Buus R, Cuzick J, Dubsky P, Kronenwett R, Denkert C, et al. Comparison of the performance of 6 prognostic signatures for estrogen receptor-positive breast cancer: a secondary analysis of a randomized clinical trial. JAMA Oncol. 2018;4:545-53.

41. Sestak I, Cuzick J, Dowsett M, Lopez-Knowles E, Filipits M, Dubsky P, et al. Prediction of late distant recurrence after 5 years of endocrine treatment: a combined analysis of patients from the Austrian breast and colorectal cancer study group 8 and arimidex, tamoxifen alone or in combination randomized trials using the PAM50 risk of recurrence score. J Clin Oncol. 2015;33:916-22.

42. Bartlett JMS, Sgroi DC, Treuner K, Zhang Y, Ahmed I, Piper T, et al. Breast Cancer Index and prediction of benefit from extended endocrine therapy in breast cancer patients treated in the Adjuvant Tamoxifen-To Offer More? (aTTom) trial. Ann Oncol. 2019;30:1776-83.

43. Noordhoek I, Treuner K, Putter H, Zhang Y, Wong J, Meershoek-Klein Kranenbarg $E$, et al. Breast Cancer Index predicts extended endocrine benefit to individualize selection of patients with $\mathrm{HR}(+)$ early-stage breast cancer for 10 years of endocrine therapy. Clin Cancer Res. 2021;27:311-9.

44. Richman J, Dowsett M. Beyond 5 years: enduring risk of recurrence in oestrogen receptor-positive breast cancer. Nat Rev Clin Oncol. 2019;16:296-311.

45. Politaki E, Agelaki S, Apostolaki S, Hatzidaki D, Strati A, Koinis F, et al. A comparison of three methods for the detection of circulating tumor cells in patients with early and metastatic breast cancer. Cell Physiol Biochem. 2017;44:594-606.

\section{AUTHOR CONTRIBUTIONS}

Conceptualisation: AK, VG; Clinical samples: KK, MN, PE; Formal analysis: AM, DH; Funding acquisition: VG; Investigation: AM, AK, VG; Methodology: SA, HP, MP Visualisation: AM, DH; Writing: AM, DH, VG; Manuscript review and approval: All authors

\section{FUNDING}

AM was supported by the Stockholm Region (clinical postdoctorial appointment, dnr K 2017-4577) and the Swedish Cancer Society (Junior Clinical Investigator award, dnr
$210277 \mathrm{JCIA} \mathrm{01).} \mathrm{This} \mathrm{work} \mathrm{has} \mathrm{been} \mathrm{financially} \mathrm{supported} \mathrm{by} \mathrm{research} \mathrm{grants} \mathrm{from}$ the Cretan Association for Biomedical Research (CABR) and the Hellenic Oncology Research Group (HORG). Open access funding provided by Karolinska Institute.

\section{COMPETING INTERESTS}

AM: consultancy to Veracyte, CA, USA (no financial compensation); AK: speaker honoraria from Astra Zeneca, MSD, Bristol Meyers Squibb, Roche and research grants from Astra Zeneca; VG: research grants from Novartis, Astelas, Astra Zeneca, Pfizer MN: speaker honoraria from Bristol Meyer Squibb, Roche, Pfizer; PE: speaker honoraria from Novartis, Astra Zeneca, MSD. The remaining authors declare no competing interests.

\section{ETHICS APPROVAL AND CONSENT TO PARTICIPATE}

The study was approved by the ethics committees at University Hospital of Heraklion, Crete and Metropolitan General Hospital, Athens. All patients provided written informed consent prior to obtaining samples. Patients that were treated within prospective randomised studies provided separate informed consent for participation in the clinical trial. This study was performed in accordance with the Declaration of Helsinki and its amendments.

\section{ADDITIONAL INFORMATION}

Supplementary information The online version contains supplementary materia available at https://doi.org/10.1038/s41416-022-01699-5.

Correspondence and requests for materials should be addressed to Alexios Matikas.

Reprints and permission information is available at http://www.nature.com/ reprints

Publisher's note Springer Nature remains neutral with regard to jurisdictional claims in published maps and institutional affiliations.

Open Access This article is licensed under a Creative Commons Attribution 4.0 International License, which permits use, sharing, adaptation, distribution and reproduction in any medium or format, as long as you give appropriate credit to the original author(s) and the source, provide a link to the Creative Commons license, and indicate if changes were made. The images or other third party material in this article are included in the article's Creative Commons license, unless indicated otherwise in a credit line to the material. If material is not included in the article's Creative Commons license and your intended use is not permitted by statutory regulation or exceeds the permitted use, you will need to obtain permission directly from the copyright holder. To view a copy of this license, visit http://creativecommons. org/licenses/by/4.0/.

(c) The Author(s) 2022 